\title{
Influence of Water-Cement Ratio on Compressive Strength of burnt bricks
}

\author{
L.Ranjith Kumar ${ }^{1}$, M.Karthikeyan ${ }^{2}$, R.Raghu ${ }^{3}$ \\ ${ }^{1}$ Assistant Professor, Panimalar Engineering College, Chennai \\ ${ }^{2,3}$ Student, Panimalar Engineering College, Chennai
}

\begin{abstract}
The study was conducted to study the effect of water-cement ratio on the compressive strength. Trial mixes were prepared using coarse aggregates only (control), at water - cement ratios of 0.4, 0.45, 0.5 and 0.55 . Cubes were prepared and tested to study the compressive strength in relation to the water-cement ratio. The results indicate that the concrete having over burnt bricks as aggregates reducing the water-cement ratio from 0.55 to 0.4 increases the compressive strength from by more than $30 \%$.
\end{abstract}

Keywords: Aggregates, concrete, compressive strength, water-cement ratio, crushed over burnt bricks

\section{Introduction}

Concrete consist of cementing substance, aggregates, water. The strength is developed from the hydration due to the reaction between cement and water. Concrete is stronger in compression than in tension, for structures required to carry only compressive loads such as massive gravity dams and heavy foundations, reinforcement is not required and the concrete is consequently called plain concrete.

At present, the most commonly used coarse aggregates for concrete is the river washed gravel due mainly to the presence of River Benue and its deposits. But these are not readily available in some local government areas which are not serviced by the river. The cost of transporting gravel to the areas outside the catchment of the river tends to increase the cost of construction even at relatively cheap labour. This necessitates the use of alternative coarse aggregates which are locally obtained. One of such coarse aggregate is crushed over burnt bricks obtained from the production of burnt.

In many countries, the need for locally manufactured building materials is an imbalance between the demands for housing and expensive conventional building materials coupled with the depletion of traditional building materials. To address this situation, attention has been focused on low-cost alternative building materials.

\section{Materials and Method}

The sand used for this project was obtained at the River. The burnt bricks samples were collected at a bricks production site. The maximum size of aggregate used was $20 \mathrm{~mm}$. Ordinary Portland cement was used as binding agent. The concrete was batched and mixed according to standards. Slump test was carried out on the fresh concrete to determine the workability of the various proportions of the gravel to crushed burnt bricks.

Table 1: Specific gravity of Materials

\begin{tabular}{|l|l|}
\hline \multicolumn{1}{|c|}{ Material } & \multicolumn{2}{c|}{ Specific Gravity } \\
\hline Cement & 3.05 \\
\hline Sand & 2.65 \\
\hline Gravel & 2.72 \\
\hline Crushed bricks & 2.15 \\
\hline Water & 1.00 \\
\hline
\end{tabular}

III. Results and Discussions

3.1 Sieve Analysis The result of the particle size distribution carried out and is presented in Tables.

Table 2 Fine Aggregate

\begin{tabular}{|l|l|l|l|}
\hline Sieve Size & Mass Retained (g) & \% Retained & \% passing \\
\hline 4.75 & 5 & 2 & 98 \\
\hline 2 & 55 & 7 & 91 \\
\hline 0.6 & 420 & 45 & 46 \\
\hline 0.2 & 380 & 40 & 6 \\
\hline 0.06 & 35 & 6 & 0 \\
\hline Pan & 4 & 0 & 0 \\
\hline
\end{tabular}


Table 3 Coarse Aggregate

\begin{tabular}{|l|l|l|l|}
\hline Sieve Size & Mass Retained (g) & \% Retained & \% passing \\
\hline 37.5 & 0 & 0 & 100 \\
\hline 25.4 & 0 & 0 & 100 \\
\hline 19.05 & 320 & 10 & 90 \\
\hline 12.70 & 1740 & 45 & 45 \\
\hline 9.5 & 950 & 27 & 18 \\
\hline 6.7 & 570 & 10 & 8 \\
\hline 4.75 & 110 & 5 & 3 \\
\hline Pan & 70 & 3 & 0 \\
\hline
\end{tabular}

\subsection{Compressive Strength}

The compressive strength results are presented in Figures. The 7 day strength increases as the proportion of burnt bricks increases and the water content reduces, reaching the highest value of $30.0 \mathrm{~N} / \mathrm{mm}^{2}$. This corresponds to proportion of 2:1 (gravel to burnt bricks). Beyond this ratio of 2:1 the strength decreases with increasing burnt bricks content, but increases as water content decreases. The 14th and 28th day strength also produces same result. The 28th day strength gives a maximum value of $35.2 \mathrm{~N} / \mathrm{mm}^{2}$ for gravel - crushed over burnt bricks ratio of $2: 1$ and water - cement ratio of 0.4

Table 1: Compressive Strength Test Results

\begin{tabular}{|c|c|c|c|c|}
\hline \multirow{2}{*}{ Ratio } & \multirow{2}{*}{ W/c } & \multicolumn{3}{|c|}{ Comp. St $\left(\mathrm{N} / \mathrm{mm}^{2}\right)$} \\
\hline & & 7 day & 14 day & 28 day \\
\hline \multirow{4}{*}{$3: 0$} & 0.4 & 26.6 & 36.8 & 39.5 \\
\hline & 0.45 & 25.2 & 30.2 & 35.4 \\
\hline & 0.5 & 23.1 & 26.5 & 28.2 \\
\hline & 0.55 & 20.2 & 24.2 & 25.4 \\
\hline \multirow{4}{*}{$2: 1$} & 0.4 & 30.2 & 34.3 & 35.2 \\
\hline & 0.45 & 29.7 & 31.2 & 30.6 \\
\hline & 0.5 & 27.4 & 29.8 & 27.4 \\
\hline & 0.55 & 22.4 & 24.4 & 25.2 \\
\hline \multirow{4}{*}{$1: 2$} & 0.4 & 29.8 & 30.2 & 31.4 \\
\hline & 0.45 & 28.6 & 29.1 & 30.5 \\
\hline & 0.5 & 26.5 & 28.5 & 29.6 \\
\hline & 0.55 & 25.4 & 27.2 & 28.4 \\
\hline \multirow{4}{*}{$0: 3$} & 0.4 & 27.6 & 29.2 & 30.2 \\
\hline & 0.45 & 26.4 & 28.4 & 29.3 \\
\hline & 0.5 & 25.4 & 26.3 & 27.4 \\
\hline & 0.55 & 24.3 & 25.5 & 26.3 \\
\hline
\end{tabular}

Fig.1 Compressive Strength at 3:0

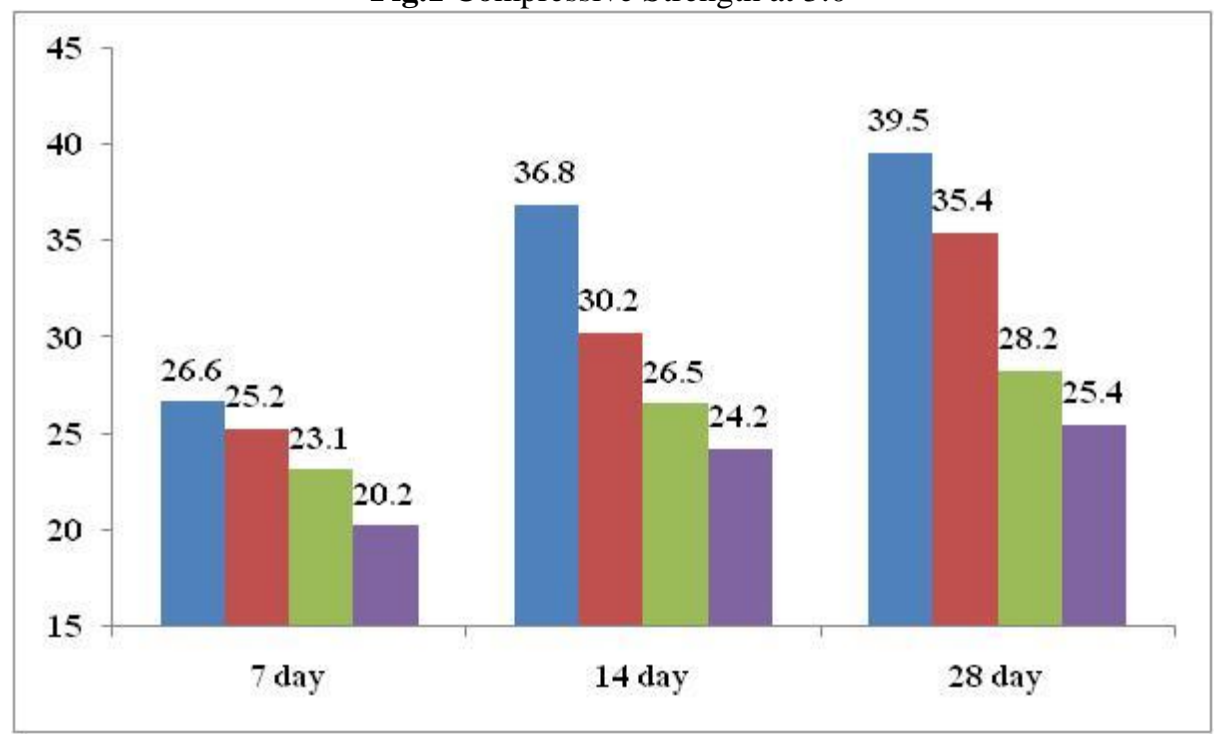


Fig.2 Compressive Strength at 2:1

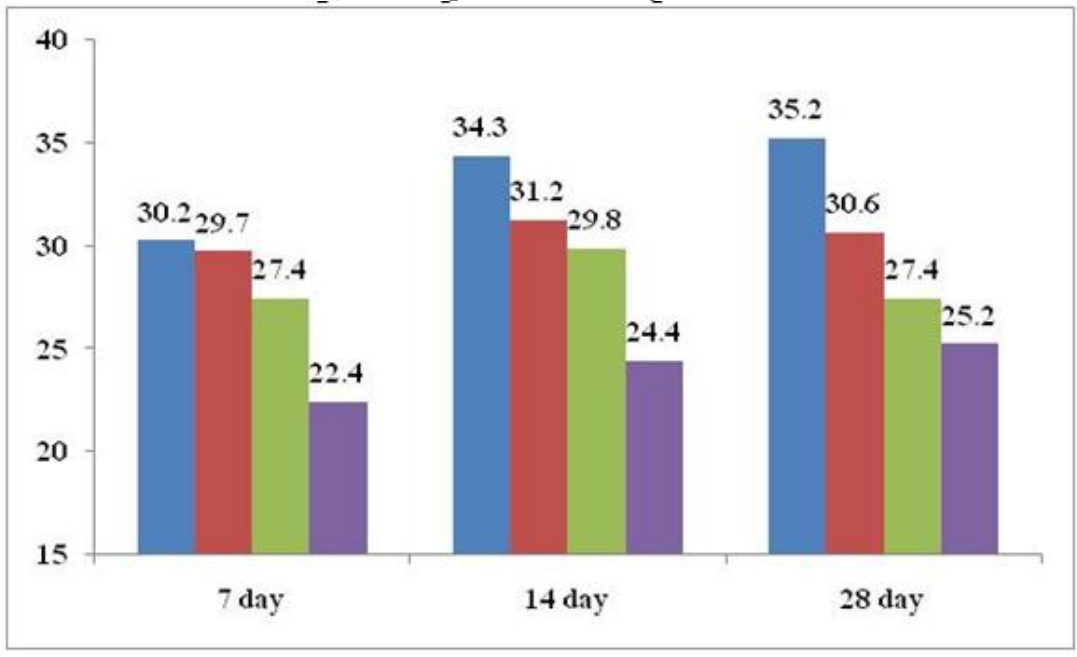

Fig.3 Compressive Strength at 1:2

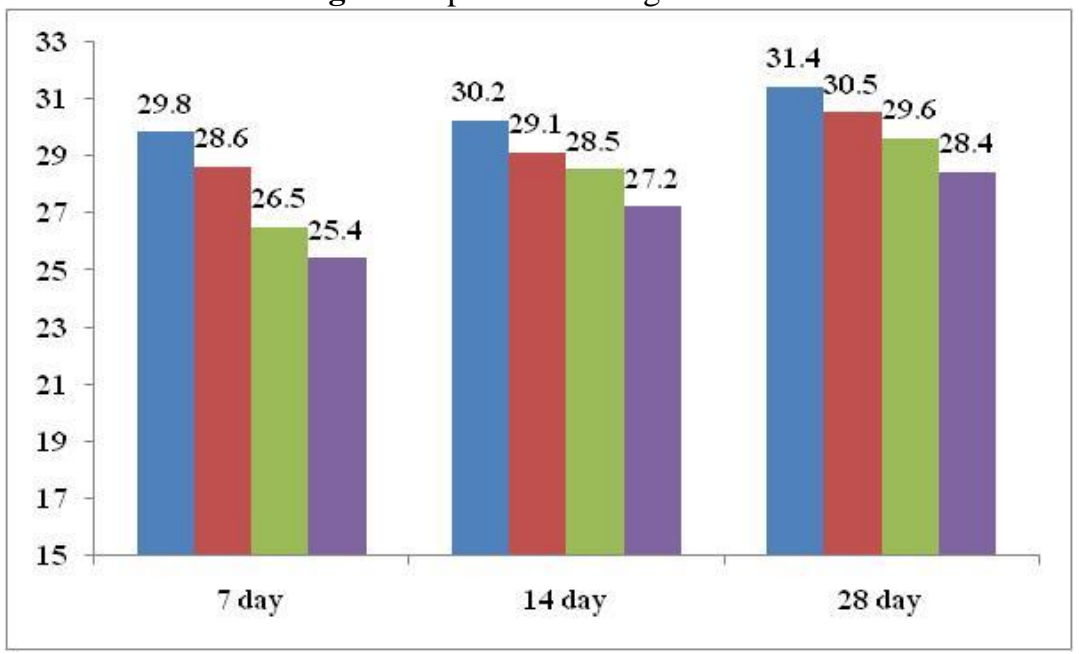

Fig.4 Compressive Strength at 0:3

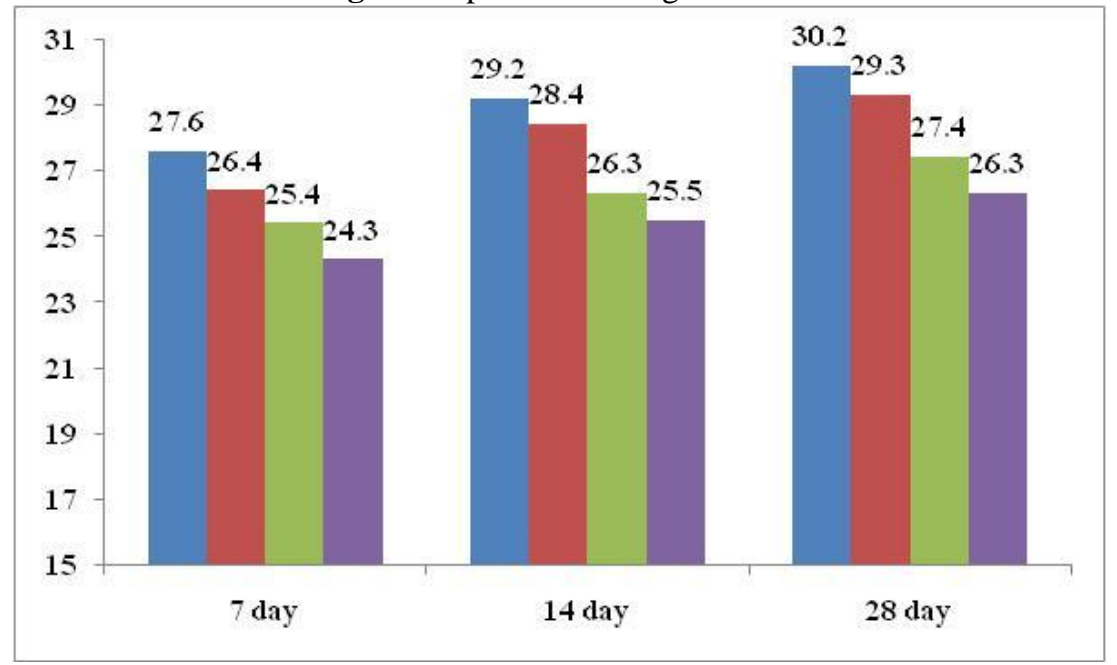

\section{Conclusion}

1) Crushed bricks concrete production.

2) Crushed bricks produce higher strength with reduction in weights

3) Reducing the w/c ratio increases the compressive strength. 


\section{Reference}

[1]. Agbede, I. O. and Manasseh, J. (2008), "Use of Cement-Sand Admixture in Laterite Brick Production for Low Cost Housing". Leonardo Electronic Journal of Practices and Technologies, pp.163-174.

[2]. Ahmad, S. and Shabir, Z. (2005), "Effect of Different Mix Ratios and Water Cement ratios on Sulphate Attack on Concrete", 30th Conference on OUR WORLD IN CONCRETE \& STRUCTUR, Singapore, 23 - 24 August.

[3]. Ahmad, S. and Shabir, Z. (2005), "Effect of Water Cement ratio on Corrosion of Reinforced concrete", 30th Conference on OUR WORLD IN CONCRETE \& STRUCTURES, Singapore, 23 - 24 August

[4]. Apebo, N. S., Iorwua, M. B. and Agunwamba, J. C. (2013), "Comparative Analysis of the Compressive Strength of Concrete with gravel and crushed over burnt bricks as coarse aggregates", Accepted December 18, 2012 for publication in Nigerian Journal of Technology, Faculty of Engineering, University of Nigeria, Nsukka, Nigeria

[5]. Bhattacharjee, E., Nag, D., Sarkar, P. P. and Haldar, L., (2011), “An Experimental Investigation of Properties of Crushed over Burnt Brick Aggregate Concrete", International Journal of Engineering Research and Technolog,. ISSN 0974-3154 Volume 4, Number 1, pp. 21-30. 